\title{
A cross-sectional study of job burnout, psychological attachment, and the career calling of Chinese doctors
}

Shu'e Zhang ${ }^{1}$, Jinghui Wang ${ }^{2}$, Fengzhe Xie ${ }^{3}$, Dong Yin ${ }^{1}$, Yu Shi', Min Zhang ${ }^{1}$, Hongyan Yin ${ }^{1}$, Fujun Li ${ }^{4}$, Libin Yang ${ }^{5}$, Depin $\mathrm{Cao}^{1,3^{*+}}$ and Tao Sun ${ }^{6^{*}+}$ (D)

\begin{abstract}
Background: The main objectives of this study were as follows: (1) evaluate the prevalence of burnout syndrome among doctors, (2) establish associations with demographic factors in China, and (3) examine the mediating role of psychological attachment in the relationship between job burnout and career calling.

Methods: This cross-sectional survey was conducted by administering an online questionnaire in May 2016. The survey was performed across Thirty provinces. In total, A total of 3016 Chinese doctors were selected as participants, of which 2617 completed valid questionnaires (effective response rate: 86.77\%).

Results: The overall prevalence of burnout symptoms among Chinese doctors was $85.79 \%$. Little variance was reported for burnout symptoms according to age (Wald $\left.x^{2}=6.843, P<0.05, O R<1\right)$, professional title (Wald $x^{2}=$ 13.110, $P<0.05, O R>1$ ), and daily working hours (Wald $x^{2}=7.226, P<0.05, O R>1$ ). However, the burnout of Chinese doctors was found to be associated with psychological attachment $(B=-0.6433, P<0.0001)$ and career calling $(B=0.3653, P<0.0001)$; furthermore, psychological attachment $(B=0.2350, P<0.001)$ mediated the relationship between job burnout and career calling.

Conclusion: Burnout symptoms among Chinese doctors were prevalent and associated with age, professional title, and long working hours. Chinese doctors aged 20-30 experienced a much higher level of burnout symptoms. The longer hours doctors worked, the more likely they were at risk of burnout symptoms, especially among attending physicians. Doctors who endured high-level burnout tended to exhibit decreasing psychological attachment, which threatened their sense of career calling. Finally, this paper proposed related explanations for the function mechanisms based on both theoretical and practical perspectives.
\end{abstract}

Keywords: Chinese doctors, Job burnout, Psychological attachment, Career calling

\section{Background}

In recent years, a series of major changes related China's medical system reform have taken place, especially regarding continuous improvement of medical service quality $[1,2]$. However, considering China's vast population and its increasing health claims, the country is

\footnotetext{
*Correspondence: caodep211@163.com; caodp211@163.com; hydsuntao@126.com

${ }^{\dagger}$ Depin Cao and Tao Sun contributed equally to this work.

'Department of Health Management, School of Health Management, Harbin Medical University, Harbin 150081, China

${ }^{6}$ Department of Health Management, School of Medicine, Hangzhou Normal University, Hangzhou 311121, China

Full list of author information is available at the end of the article
}

facing a certain systemic crisis, including an insufficient number of doctors and an imbalanced structure of supply-demand within health services. Inescapably, Chinese doctors are suffering the stressful work conditions characterised by excessive workloads, high occupational stress, effort-reward imbalances, potential health risks, tolerance of customer's rude behaviour, [3] and so on. Daily, they endure fatigue, frustration, and with patients while providing services [4], which increases burnout. To make matters worse, tired doctors can easily trigger further negative outcomes, $[2,5,6]$ such as deterioration of doctor-patient relationships [7] and escalated violence in the health care sector [7]. Therefore, it 
is understandable that professional burnout among doctors has drawn continuous attention among academics and the public worldwide. Similarly, the various adverse effects resulting from doctor burnout also merit constant attention, which raises the question: given these deteriorating professional environments, how do doctors evaluate their own careers given that they are under tremendous stress and experiencing burnout? Particularly for doctors in highly challenging situations, 'career calling' can be regarded as a personal resource which provides their lives with meaning, increased resilience, and mechanisms for coping with challenges, further buffering the wider effects of burnout [8]. However, the neverending series of patient complaints and array of negative emotions triggered by job burnout are likely to reduce doctors' job satisfaction, organizational commitment, and psychological attachment to the hospital setting, ultimately resulting in lower career expectations and less motivation to pursue a career in medicine [8]. It is interesting to study how burnout affects doctors' sense of career calling and whether psychological attachment plays a specific role in this relationship. However, the topic of the 'career calling' of doctors has received little international academic attention. This means that the more extensive adverse effects of doctor burnout are likely being ignored. Hence, the present study contributes to the literature by demonstrating the correlation between doctor burnout, psychological attachment, and career calling, as well as to verify possibly existing mechanism.

\section{What is 'job burnout'?}

'Job burnout' is regarded as a psychological syndrome involving chronic emotional and interpersonal stressors referring to individuals' experiences at work and their subsequent responses to their tasks, organizations, coworkers, clients, and themselves $[9,10]$. In the past half century, symptoms of burnout have been confirmed to exist within a wide range of human service professionals, and related research on job burnout has been undertaken extensively by scholars in various fields $[9,10]$. A wellknown and widely-accepted burnout model is Maslach's three-dimensional model, [11] which includes variables such as emotional exhaustion, depersonalisation, and reduced personal accomplishment. Of these, emotional exhaustion is the core variable and is regarded as a kind of 'negative' mindset [11]. The Shirom-Melamed Burnout Measure is also popular among experts and serves as a well-known authority for explaining the issue of job burnout [12]. Pine believes that job burnout is an amalgam of both physical and psychological fatigue caused by longterm emotional deprivation [12]. Shirom and Melamed further define job burnout as a kind of mental state due to an exhaustion of physical, emotional, and cognitive energy
[12]. Known as a 'job killer', burnout is likely to threaten an individual's health, obstruct an organization's performance, and may even cause serious social problems [13]. On the individual level, job burnout can cause serious problems such as headaches, insomnia, reduced work efficiency, impaired concentration, memory deterioration, poor immune system, [9] and so forth. Furthermore, mental health symptoms commonly caused by burnout have been verified and include anxiety, depression, and feelings of inferiority [9] which can lead to an employee's poor quality of day-to-day working environment and family relationships as well as diminished self-image and happiness [13]. At an organizational level, an individual's burnout symptoms are prone to influencing their team members, resulting in an overall deterioration of organizational morale and reduced efficiency of organizational operations [14]. A previous study has indicated that burnout may be linked to 'escapism' behaviour; for instance, job withdrawal and turnover may increase at significant cost to the organization [9]. Many studies have confirmed that the high prevalence of job burnout is closely related to worsening occupational environments, [9] which, in turn, causes a lack of harmony in interpersonal relationships and more occupational hazards [15]. However, the adverse effects caused by doctor burnout are a growing concern worldwide, and are far broader in scope than the results of this study demonstrate. Hence, further research still needs to be conducted, especially in healthcare setting where the effects of job burnout are potentially life-threatening [16].

\section{What happens when doctors experience job burnout?}

The term 'burnout' has taken on a broad meaning that goes far beyond what is understood about it as a diagnosis or syndrome [17]. Therefore, how do we approach the issue of physician burnout in the medical profession? [18]. Burnout among doctors is an extensive problem, and their symptoms may not only threaten their health and sleep quality [10], but also the quality of the medical services that they provide and the well being of their patients, even their very lives, which restricts the advancement of China's healthcare system reforms [15]. Numerous studies have found that doctor burnout is associated with a higher frequency of medical errors, lower patient satisfaction, longer post-discharge recovery times, and decrease in professional drive, lapses in professionalism, impeded learning, problematic alcohol use, and low job satisfaction [17]. Burnout tends to worsen and change over time, and the issue of doctor burnout is exhibiting an obvious increasing trend [17]. Today, there are still some problems in China's health care system. To counterbalance what may be seen as dissatisfying reward for their efforts, some doctors are emphasising economic benefit rather than providing their patients with the best possible health care [19]. Even worse, there is a widespread sense that the career calling of doctors is 
gradually weakening, and the formerly trusting relationships between doctors and patients have been broken, which will be difficult to mend in the short term $[1,20]$. An increase in doctors' unprofessional and unethical behaviour induced by burnout could likely lead to more occurrences of violence towards doctors, [21] which also poses additional difficulties to reforming the healthcare system. The present study continues to focus on the current situation regarding burnout among physicians and its adverse results in the Chinese context in order to make a significant contribution to understanding the phenomenon of doctor burnout.

\section{What is the relationship between career calling, psychological attachment, and doctor burnout?}

Career calling is defined as an approach to one's work in which one is inspired by an 'external summons' and provided with a means through which one is able to derive meaning and fulfil positive social functions [8]. Specifically, career calling is related to so-called 'career spirit [8]; that is, providing services for people, promoting physical and mental harmony, and improving people's quality of life [8]. Vital research has found that career calling is linked to work effort, dedication, and well-being [22]. A sense of career calling is particularly important for doctors in highly challenging situations. Consequently, a correct and profound understanding of the medical profession is a necessary component of a career calling for any doctor $[10,23]$. While there has already been much scholarly discussion about career calling, [23] these studies have mostly focused on understanding its core concepts [24]. There has been little research into the association between the career calling and burnout of doctors [10]. In China, where these issues are particularly problematic, questions of falling career calling and increased burnout are grossly neglected by academics and not reflected in systemic health care reforms. There is no doubt that it is essential to monitor these issues as they unfold and explore the relationship between doctors' career calling and burnout in depth.

Doctors exhibit reduced enthusiasm for their work due to emotional exhaustion, a decline in professional meaningfulness, job satisfaction, and organizational identification [25]. When doctors are treated unfairly, their enthusiasm diminishes with in-role weakening and extrarole decreasing, [26] resulting a loss of psychological attachment to their organization [26]. 'That special attachment', as Hirschman calls the loyalty psychologists term 'effective commitment [27] -is an 'employee's emotional attachment to, identification with, and involvement in the organization $[28,29]$. Doctors with high levels of attachment are prone to identifying with their career goals and values as well as a sense of pride regarding their profession; thus, they tend to undertake behaviour which extend beyond the job's in-role requirements [30]. Therefore, we can assume that, if the degree of a doctor's psychological attachment decreases, his or her acceptance of and emotional dependence on his or her sense of career calling (i.e., the reason he or she became a doctor in the first place) would diminish. However, previous studies have revealed that attachment plays a mediating role in many relationships [31]. Only a few studies have explored the notion that psychological attachment may mediate the relationship between job burnout and career calling among doctors. To remedy this gap in the literature, in this study, we examined psychological attachment using a function mechanism to test the mediating effect of psychological attachment. More importantly, the findings of this study contribute to new evidence increasingly revealing the adverse effects caused by the job burnout of Chinese doctors, specifically, negative effects on psychological attachment and career calling.

\section{What are the objectives of this study?}

This study comprehensively investigated the following research questions: (1) how prevalent is burnout syndrome among doctors, and what differences in demographic factors can be established? (2) What is the relationship between job burnout, psychological attachment, and career calling? (3) How does job burnout threaten doctors' career calling and does psychological attachment play a specific role in the relationship between burnout and career calling?

\section{Methods}

\section{Subjects and procedures}

A snowball sampling methodology was used to collect the data through the network investigation. Doctors from across China completed an anonymous online questionnaire in May 2016. A total of 3016 participants distributed across 30 cities participated in the survey, the HeiLongJiang $(38.00 \%)$ province where the initial sample was recruited. The proportion of the other 29 provinces was ShanDong (17.00\%), HuNan (6.00\%), BeiJing (3.00\%), GuangDong (3.00\%), ZheJiang (3.00\%), JiangSu (3.00\%), LiaoNing (2.00\%), JiLin $(2.00 \%)$ and others (19.0\%), and 2617 valid questionnaires were used as the samples (an effective response rate of $86.77 \%$ ). First, a sampling frame was set up, approximately 50 doctors from the authors' unit were selected as the original deliverers of the survey. Subsequently, they were fully informed of the purpose and significance of this study and their positive cooperation was obtained. Then the colleagues or classmates of 'the original deliverers' were invited to participate in our online survey. Meanwhile, the remaining doctors were colleagues invited by the initial participants. An anonymous online questionnaire was used to collect data, and anyone could obtain 
the Website Lucky Money as an award after they answered the questionnaire.

Our final sample was selected with strict adherence to exclusion criteria for data management and quality control. Inclusion criteria were as follows: doctors must be Chinese, give informed consent for participation, and participate voluntarily. Exclusion criteria included: no answer, voluntarily withdrawing from the study by failing to answer all the questions, too many missing items or obvious response errors, taking too little or long to respond.

\section{Representativeness and comparability}

The general characteristics of the study participants (age, gender, service years, education level and professional title) were compared to those of Chinese doctors which were included in the Chinese Health and Family Planning Statistical Yearbook [32](CHFPSY) report on practicing physician published in 2016. Currently, this is the authority source concerning the characteristics of practicing physicians available. In addition, the results of the study participants group and the results of the CHFPSY members group were analyzed separately and then compared to determine the homogeneity of the sample [33].

\section{Measures}

This study consisted of four questionnaires. Demographic variables were gathered using a self-designed questionnaire and included age, gender, education level, professional title, marital status, hospital level, service years, and so on.

\section{Measurement of job burnout}

$\mathrm{Li}$ et al.'s Job Burnout Inventory with 15 revised items was used to measure the three dimensions of burnout (emotional exhaustion, depersonalization, and reduced personal accomplishment) [34]. This Job Burnout Inventory in medica settings was demonstrated to have good reliability and validity $[35,36]$. Items were scored on a seven-point Likert scale ranging from 0 ('totally disagree') to 6 ('totally agree') where higher scores represented a higher degree of job burnout. The Cronbach's alpha coefficient of the scale was 0.882 . Maslach's threedimensional model includes (1) emotional exhaustion (EE), (2) depersonalization (DA), and (3) reduced personal accomplishment (PA) [11]. In this study, the scores of the three dimensions of burnout were as follows: (1) EE: low (<11), medium (11-15), and high (>15); (2) DA: low $(<9)$, medium (9-12), and high $(>12)$; and (3) PA: low $(<19)$, medium (19-22), and high $(>22)[35,36]$. Maslach's cut-off scores for EE, DA, and reduced PA are 25,11 , and 16, respectively [37]. According to the scores for these three dimensions, the model then divides job burnout into four levels: (1) no burnout (all three scores are less than cut-off), (2) mild burnout (one of the three scores is greater than or equal to cut-off), (3) moderate burnout (two of the three scores are greater than or equal to cut-off), and (4) severe burnout (all three scores are greater than or equal to cut-off) [37].

\section{Measurement of psychological attachment}

The psychological attachment inventory by Burris et al. with 4 items revised was used to measure the Chinese doctors' psychological attachment level [31]. The crosscultural adaptability of the psychological attachment inventory has been examined in other studies [38]. The psychological attachment inventory was applied to Chinese doctors for the first time. Items were scored on a five-point Likert scale ranging from 1 ('totally disagree') to 5 ('totally agree'), where higher scores represented a higher degree of the psychological attachment. The Cronbach's alpha coefficient of the scale was 0.920 .

\section{Measurement of career calling}

To assess doctors' career calling level, we used the 4item Career Calling Scale revised by Dik et al. [39]. The cross-cultural adaptability of the Career Calling Scale has been examined in other studie s in China [40]. The Career Calling Scale was applied to Chinese doctors for the first time. Items were scored on a five-point Likert scale ranging from 1 ('totally disagree') to 5 ('totally agree'), where higher scores represented a higher degree of career calling. The Cronbach's alpha coefficient of the scale was 0.786 .

\section{Statistical analysis}

All data were collected using a cross-sectional survey and analyses were performed using the SPSS 22.0 program (SPSS, Inc., Chicago, IL). Descriptive statistical analysis was used to describe the data collected. An internal consistency reliability test was performed to check inventory reliability, and logistic regression analysis was conducted to examine differences among demographic variables. We provided values including F, R2, and R2changes, and the fit of the model was assessed with R2. Unstandardized regression coefficients (B), standard error (SE), and $P$ values were reported for each step in the regression model. Statistical significance was defined as $\mathrm{P}<0.05$ (two-tailed).

\section{Ethics statement}

The Institutional Review Board (IRB) of Harbin Medical University approved this study. Since the survey was anonymous, it was impossible to obtain informed written consent. In this case, an informed consent form was included at the beginning of the questionnaire. Completing the questionnaire was therefore considered informed consent' for participation in the survey. Confidentiality was maintained for all information collected in the survey. 
Table 1 Socio-demographic characteristics of the respondents $(n=2617)$

\begin{tabular}{|c|c|c|}
\hline Characteristic & Number & Percent \\
\hline \multicolumn{3}{|l|}{$\overline{\text { Age }}$} \\
\hline $20-30$ & 587 & 22.4 \\
\hline $31-40$ & 1224 & 46.8 \\
\hline $41-50$ & 658 & 25.1 \\
\hline $51+$ & 119 & 4.5 \\
\hline Unsure & 29 & 1.1 \\
\hline \multicolumn{3}{|l|}{ Service Years } \\
\hline $0-10$ & 1088 & 41.6 \\
\hline $11-20$ & 720 & 27.5 \\
\hline $20+$ & 376 & 14.4 \\
\hline Unsure & 433 & 16.5 \\
\hline \multicolumn{3}{|l|}{ Hospital level } \\
\hline Tertiary hospitals & 1740 & 66.6 \\
\hline Second-class hospital & 733 & 28.1 \\
\hline Primary hospital & 139 & 5.3 \\
\hline Missing value & 5 & 2.0 \\
\hline \multicolumn{3}{|l|}{ Gender } \\
\hline Male & 1240 & 47.4 \\
\hline Female & 1369 & 52.3 \\
\hline Unsure & 8 & 3.0 \\
\hline \multicolumn{3}{|l|}{ Education level } \\
\hline College degree or below & 291 & 11.1 \\
\hline Bachelor & 1350 & 51.7 \\
\hline Master & 692 & 26.5 \\
\hline Doctor & 277 & 10.6 \\
\hline Unsure & 7 & 3.0 \\
\hline \multicolumn{3}{|l|}{ Marital status } \\
\hline Unmarried & 397 & 15.2 \\
\hline Married & 2148 & 82.1 \\
\hline Divorce or loss of spouse & 70 & 2.7 \\
\hline Unsure & 2 & 1.0 \\
\hline \multicolumn{3}{|l|}{ Professional title } \\
\hline Without professional title & 306 & 11.7 \\
\hline Resident doctor & 564 & 21.6 \\
\hline Attending physician & 898 & 34.4 \\
\hline Associate chief physician & 569 & 21.8 \\
\hline Chief Physician & 270 & 10.4 \\
\hline Unsure & 10 & 4.0 \\
\hline \multicolumn{3}{|l|}{ Shift work } \\
\hline Often work during the day & 503 & 19.2 \\
\hline Occasional work at night & 500 & 19.1 \\
\hline Often work at night & 1613 & 61.6 \\
\hline Unsure & 1 & 0.1 \\
\hline
\end{tabular}

Table 1 Socio-demographic characteristics of the respondents $(n=2617)$ (Continued)

\begin{tabular}{lll}
\hline Characteristic & Number & Percent \\
\hline Daily working hours (hours) & & \\
$0-8$ & 528 & 20.2 \\
$9-10$ & 1297 & 49.6 \\
$11-12$ & 504 & 19.3 \\
$13+$ & 285 & 10.9 \\
Unsure & 3 & 0.1 \\
\hline
\end{tabular}

\section{Results}

Demographic information for samples

The representativeness of the responding physicians was evaluated by comparing characteristics of the study participants with those of Chinese doctors which were published in Chinese Health and Family Planning Statistical Yearbooks, regarding age groups distribution $(22.40 \%$ under 30 years in study participants vs $22.10 \%$ in the CHFPSY report), gender ( $47.40 \%$ vs $55.90 \%$ males), service years $(16.50 \%$ under 30 service years in study participants vs $23.40 \%$ in the CHFPSY report) and education level (44.30\% vs $51.70 \%$ bachelor in the CHFPSY report). In this study, participants' demographic variables are shown in Table 1.

\section{The incidence of job burnout and the three dimensions}

The status of Chinese doctors' job burnout is shown in Table 2. Among 2617 participating Chinese doctors, a total of 2245 reported experiencing varying degrees of job burnout over the past years. The overall prevalence of all degrees of burnout was $85.79 \%$, and the breakdown according to severity is as follows: 713 (40.0\%) mild, 1233 (27.2\%) moderate and 299 (7.4\%) severe burnout.

\section{Total burnout-univariate analysis}

The analysis of the factors influencing Chinese doctor job burnout is shown in Table 3. One of the classification variables was intentionally set as a 'dummy' variable. Univariate logistic regression analysis of the development dataset (2617 doctors) included in the equation was as follows: (1) job burnout as dependent variable (never $=0$, exist $=1$ ); (2) doctor's age $(20-30=1,31-40=2,41-50=3,51+=4)$; (3) gender $\quad($ male $=1$, female $=2)$; (4) education level (college degree or below $=1$, bachelors $=2$, masters $=3$, doctorate $=$ 4); (5) professional title (without professional title $=1$, resident physician $=2$, attending physician $=3$, associate chief physician $=4$, chief physician $=5$ ); (6) marital status (unmarried $=1$, married $=2$, divorced or loss of spouse $=3$ ); $(7)$ hospital level (tertiary hospitals $=1$, secondary hospital $=2$, primary hospital =3); and (8) number of daily working hours (in hours). According to our results, most doctors $(85.79 \%)$ exhibited varying degrees of job burnout. Age 
Table 2 Values are numbers (percentages) of respondents regarding job burnout $(n=2617)$

\begin{tabular}{|c|c|c|c|c|c|}
\hline Variables & & N & $\%$ & M & SD \\
\hline \multirow[t]{3}{*}{ Emotional exhaustion } & mild & 193 & 7.4 & 19.35 & 6.24 \\
\hline & moderate & 518 & 19.8 & & \\
\hline & severe & 1899 & 72.8 & & \\
\hline \multirow[t]{3}{*}{ Depersonalization } & mild & 726 & 27.8 & 12.89 & 5.50 \\
\hline & moderate & 647 & 24.8 & & \\
\hline & severe & 1241 & 47.5 & & \\
\hline \multirow[t]{3}{*}{ Reduced personal accomplishment } & mild & 950 & 36.5 & 20.67 & 7.29 \\
\hline & moderate & 329 & 12.6 & & \\
\hline & severe & 1327 & 50.9 & & \\
\hline \multirow[t]{4}{*}{ Job burnout } & never & 353 & 13.49 & 52.90 & 14.02 \\
\hline & mild & 713 & 27.24 & & \\
\hline & moderate & 1233 & 47.12 & & \\
\hline & severe & 299 & 11.43 & & \\
\hline
\end{tabular}

(Wald $x^{2}=7.231, \quad P<0.01, \quad$ OR $<1$ ), education level (Wald $X^{2}=9.751, \quad P<0.05, \quad$ OR $>1$ ), $\quad$ professional title (Waldx ${ }^{2}=14.969, \mathrm{P}<0.01, \mathrm{OR}>1$ ) and daily working hours (Waldx $^{2}=11.942, \mathrm{P}<0.01$, OR $>1$ ) were the factors most related to job burnout. These four factors were then entered into the multivariate logistic regression model.

\section{Total burnout-multivariate analysis}

Further screening of the factors influencing doctor job burnout are shown in Table 4 . We analysed the four factors selected by the univariate logistic regression analysis using multivariate factor logistic regression analysis. According to Table 4, the result of the significance test of the whole regression model was $X^{2}=37.872(P=0.001$, $P<0.01$ ), while the result of the Hosmer-Lemeshow test was $2.132(P=0.977, P>0.05)$; therefore, these regression models were optimal. As shown in Table 4, the results of the tests concerning the variables of age ( Wald $^{2}=6.790, P<0.05, O R<1$ ), daily working hours (Wald $\left.\chi^{2}=7.226, P<0.01, O R>1\right)$ and professional title ( Wald $\left.\chi^{2}=13.110, P<0.01, O R<1\right)$ were significant, suggesting that these factors are the significant predictors of job burnout among Chinese doctors.

\section{Psychological attachment as a mediator of the associations between job burnout and career calling}

The means, standard deviations, and Pearson's correlation coefficients of the continuous variables are presented in Table 5. All the variables were significantly correlated with one another, and job burnout was negatively correlated with psychological attachment $(r=-$ 0.577, $p<0.01)$ and career calling $(r=-0.422, p<0.01)$. There was also a positive correlation between psychological attachment and career calling $(r=0.543, p<0.01)$. The absolute value of the correlation coefficient was between 0.25 and 0.65 , which indicated that each variable could be used in the subsequent regression analyses.

Psychological attachment was tested as a possible mediator of the relationship between job burnout and career calling. The mediator was tested by calculating biascorrected 95\% confidence intervals using bootstrapping with $N=5000$ resamples via the PROCESS procedure for SPSS22.0 [41]. Hierarchical linear regression analysis was performed to examine the relationship between job burnout, career calling, and psychological attachment (Table 6 M1-4) after eliminating the effects of demographic variables (age, gender, marital status, hospital level, professional title, educational level, and hospital department). This study regarded 'job burnout' as the independent variable, 'psychological attachment' as the mediator variable, and 'career calling' as the dependent variable. We found that psychological attachment had a significantly positive influence on career calling $(B=$ 0.3653, $P<0.0001$ ), and that the job burnout of Chinese doctors had a significantly negative influence on psychological attachment $(\mathrm{B}=-0.6433, \mathrm{P}<0.0001)$ and career calling $(\mathrm{B}=-0.3873, \mathrm{P}<0.0001)$. Moreover, psychological attachment played a mediating role between job burnout and career calling $(\mathrm{B}=-0.3653, \mathrm{P}<0.0001)$. The indirect effect of job burnout on career calling was found to be -0.2350 , and the direct effect of job burnout on career calling through psychological attachment was found to be -0.1523 . The total effect of job burnout on career calling was -0.3873 .

\section{Discussion}

The status of the Chinese doctor job burnout

The results of the present survey indicated that the overall prevalence of burnout among Chinese doctors 
Table 3 Univariate logistic regression analysis of respondents $(n=2617)$

\begin{tabular}{|c|c|c|c|c|c|c|}
\hline Variables & B & S.E. & Wald & Df & $\mathrm{P}$ & OR \\
\hline \multicolumn{7}{|l|}{ Age (contrast $=20-30)$} \\
\hline $31-40$ & 0.158 & 0.151 & 1.101 & 1 & 0.294 & 1.172 \\
\hline $41-50$ & -0.181 & 0.163 & 1.239 & 1 & 0.266 & 0.835 \\
\hline $51+$ & -0.651 & 0.251 & 6.742 & 1 & 0.009 & 0.522 \\
\hline \multicolumn{7}{|l|}{ Gender (contrast $=$ male) } \\
\hline Gender: female & 0.184 & 0.115 & 2.541 & 1 & 0.111 & 1.202 \\
\hline Education level (contrast = college degree or below) & & & 9.751 & 3 & 0.021 & \\
\hline Education level: bachelor & 0.303 & 0.172 & 3.101 & 1 & 0.078 & 1.354 \\
\hline Education level: master & 0.605 & 0.197 & 9.450 & 1 & 0.002 & 1.832 \\
\hline Education level: doctor & 0.288 & 0.231 & 1.553 & 1 & 0.213 & 1.333 \\
\hline Professional title (contrast $=$ without professional title) & & & 14.969 & 4 & 0.005 & \\
\hline Professional title: resident doctor & 0.422 & 0.199 & 4.488 & 1 & 0.034 & 1.525 \\
\hline Professional title: attending physician & 0.383 & 0.182 & 4.453 & 1 & 0.035 & 1.467 \\
\hline Professional title: associate chief physician & 0.474 & 0.200 & 5.609 & 1 & 0.018 & 1.606 \\
\hline Professional title: chief physician & -0.132 & 0.216 & 0.371 & 1 & 0.542 & 0.877 \\
\hline Martial status (contrast = unmarried) & & & 5.958 & 2 & 0.051 & \\
\hline Martial status: married & -0.370 & 0.176 & 4.411 & 1 & 0.036 & 0.691 \\
\hline Martial status: divorce or loss of spouse & 0.211 & 0.458 & 0.213 & 1 & 0.644 & 1.235 \\
\hline Hospital level (contrast = tertiary hospitals) & & & 2.993 & 2 & 0.224 & \\
\hline Hospital level: second-class hospital & -0.175 & 0.127 & 1.914 & 1 & 0.167 & 0.839 \\
\hline Hospital level: primary hospital & -0.302 & 0.239 & 1.588 & 1 & 0.208 & 0.740 \\
\hline Daily working hours & 0.234 & 0.068 & 11.942 & 1 & 0.001 & 1.264 \\
\hline
\end{tabular}

was $85.79 \%$ with a breakdown in severity as follows: 713 (40.0\%) mild, 1233 (27.2\%) moderate, and 299 (7.4\%) severe. This result implied that Chinese doctors experienced different degrees of job burnout in the past year. Compared with the data from the United States [42] and Canada, [43] the symptoms of job burnout

Table 4 Multivariate logistic regression analysis of respondents $(n=2617)$

\begin{tabular}{|c|c|c|c|c|c|c|c|}
\hline Variables & B & S.E. & Wald & Df & $P$ & OR & Correlation strength \\
\hline Daily working hours & 0.187 & 0.070 & 7.241 & 1 & 0.007 & 1.206 & \multirow{16}{*}{$\begin{array}{l}\text { Cox-Snell R2 }=0.015 \\
\text { Nagelkerke R2 }=0.027\end{array}$} \\
\hline Age (contrast = 20-30) & & & 6.790 & 3 & 0.079 & & \\
\hline $31-40$ & -0.094 & 0.192 & 0.238 & 1 & 0.626 & 0.910 & \\
\hline $41-50$ & -0.436 & 0.246 & 3.126 & 1 & 0.077 & 0.647 & \\
\hline $51+$ & -0.742 & 0.329 & 5.087 & 1 & 0.024 & 0.476 & \\
\hline Education level (contrast = college degree or below) & & & 3.332 & 3 & 0.343 & & \\
\hline Education level: bachelor & 0.132 & 0.192 & 0.477 & 1 & 0.490 & 1.141 & \\
\hline Education level: master & 0.338 & 0.219 & 2.382 & 1 & 0.123 & 1.401 & \\
\hline Education level: doctor & 0.044 & 0.263 & 0.028 & 1 & 0.867 & 1.045 & \\
\hline Professional title (contrast $=$ without professional title) & & & 9.287 & 4 & 0.054 & & \\
\hline Professional title: resident doctor & 0.329 & 0.213 & 2.392 & 1 & 0.122 & 1.390 & \\
\hline Professional title: attending physician & 0.412 & 0.235 & 3.072 & 1 & 0.080 & 1.510 & \\
\hline Professional title: associate chief physician & 0.696 & 0.280 & 6.191 & 1 & 0.013 & 2.005 & \\
\hline Professional title: chief physician & 0.237 & 0.318 & 0.556 & 1 & 0.456 & 1.267 & \\
\hline Constant & 1.123 & 0.243 & 21.288 & 1 & 0.001 & 3.073 & \\
\hline Overall model fit test & \multicolumn{6}{|c|}{ X2 $=37.805$ Hosmer-Lemeshow $=6.213$} & \\
\hline
\end{tabular}


Table 5 Means, standard deviations (SD), and correlations of continuous variables $(n=2617)$

\begin{tabular}{llllll}
\hline Variables & M & S D & Job burnout & Psychological attachment & Career calling \\
\hline Job burnout & 3.526 & 0.934 & 1.000 & 1.000 \\
Psychological attachment & 2.698 & 1.134 & $-0.557^{* *}$ & $0.543^{* *}$ & 1.000 \\
Career calling & 3.020 & 0.959 & $-0.422^{* *}$ & \\
\hline
\end{tabular}

${ }^{* *} P<0.01$, Correlation is significant at the 0.01 level (2-tailed)

were the most serious among Chinese doctors. Additionally, compared with other professions, [44] Chinese doctors seemed to experience more prevalent burnout symptoms. Consequently, these results provided clear evidence that hospital managers as well as the Chinese government should pay more attention to this severe public health issue in the future.

\section{Influencing factors of Chinese doctor job burnout}

The present study found that the level of job burnout among Chinese doctors was most significant for the variables of age, daily working hours and professional title. In China, doctors' professional titles are developed by health administrations and hospitals to better manage physicians. They represent the medical skill level of doctors, which is generally divided into undetermined physician assistants, resident doctors, attending physicians, associate chief physicians and chief physicians from low to high. Younger doctors and attending physicians reported they had experienced more serious symptoms of job burnout, which is consistent with previous research [45]. When younger and attending physicians surpassed their physiological and psychological limits, they likely failed to meet excessive role demands [46]. During their first five years of medical training, young physicians are required to master complex procedural tasks and skills [10] as well as produce academic research. Stress, therefore, has an unquestioned significance in the burnout phenomenon, particularly when it is persistent [47]. In China, younger physicians, especially attending physicians, often suffer from all kinds of pressure in the workplace, such as role overload, unruly patients, and less work experience, which further results in job burnout [48]. In contrast, [42] older doctors with extensive experience who occupy higher positions are likely to receive more respect and adequate rewards as well as experience fewer role conflicts [42]. On the other hand, older doctors have mastered how to adjust their work rhythms and relieve stress, minimising the risk of job burnout [49]. In this sense, physicians are more at risk of experiencing burnout symptoms earlier in their careers [45].

One result of this study which was consistent with a previous study [45] was that the rates of severe job burnout were higher as working hours increased. On average, Chinese doctors work over $10 \mathrm{~h}$ per day [50]. In situations where the pressure to work longer hours is high, doctors have less time for sleep, personal relationships, and family activities [10]. Therefore, doctors may omit many duties and obligations from their family roles, which can contribute to higher stress and fatigue, greater work-life imbalance, and more work-family conflicts, [48] further aggravating burnout [51]. Moreover, doctors consume a large amount of physical and mental energy during their long hours of overtime, which facilitates the development of negative attitudes toward their work [52] and increases physiological fatigue and emotional exhaustion $[46,50,53]$.

\section{Psychological attachment as mediators of the associations between job burnout and career calling} The results of the present study demonstrated the significant negative impact of job burnout on career calling, which is in accord with previous studies [10]. In addition,

Table 6 Hierarchical linear regression models of mediation $(n=2617)$

\begin{tabular}{|c|c|c|c|c|c|c|}
\hline Model & B & $S E$ & $\begin{array}{l}\text { Test } \\
\text { statistic }\end{array}$ & $\begin{array}{l}P- \\
\text { value }\end{array}$ & $\begin{array}{l}95 \% \text { CI (LLUI- } \\
\text { ULCI) }\end{array}$ & \\
\hline $\begin{array}{l}\text { M1 Job burnout for Psychological } \\
\text { attachment }\end{array}$ & -0.6433 & 0.0222 & -28.9340 & 0.0001 & $(-0.6869-0.5997)$ & $\begin{array}{l}R=0.5570 ; R-s q=0.3102 ; F=1249.3620 ; p= \\
0.0001\end{array}$ \\
\hline $\begin{array}{l}\text { M2 Psychological attachment for career } \\
\text { calling }\end{array}$ & 0.3653 & 0.1830 & 19.9716 & 0.0001 & (0.3296 0.4012) & $\begin{array}{l}R=0.5504 ; R-s q=0.3029 ; F=114.4493 ; p= \\
0.0001\end{array}$ \\
\hline $\begin{array}{l}\text { M3 Job burnout for career calling (direct } \\
\text { effect) }\end{array}$ & -0.1523 & 0.0221 & -6.9013 & 0.0001 & $\begin{array}{l}(-0.1956- \\
0.1090)\end{array}$ & \\
\hline $\begin{array}{l}\text { M4 Job burnout for career calling (total } \\
\text { effect) }\end{array}$ & -0.3873 & 0.0204 & -19.0255 & 0.0001 & $\begin{array}{l}(-0.4273- \\
0.3474)\end{array}$ & $\begin{array}{l}R=0.4135 ; R-s q=0.1710 ; F=62.0979 ; p= \\
0.0001\end{array}$ \\
\hline
\end{tabular}

The indirect effect of job burnout on career calling was -0.2350

The direct effect of job burnout on career calling was -0.1523

The total effect of job burnout on career calling was -0.3873 
this study also found that psychological attachment played a partial mediating role between job burnout and career calling. A high level of job burnout decreased doctors' psychological attachment toward their organization and reduced their career calling.

According to the stress theory, [54] doctors' stressful professional contexts largely foster a kind of professional burnout which can be considered as part of an individual's process of changing his or her professional attitudes and behaviours in a negative manner [55]. In China, the many problems in hospital settings include poor working conditions, work overload, lack of appropriate remuneration, and a malfunctioning health care system,which may help explain why many excellent younger doctors develop negative professional attitudes and behaviours as well as to low-psychological attachment [47]. Psychological attachment can invigorate the doctors' spirits because it encourages doctors to make efforts on behalf of their medical organization. However, as seen in this study, when experiencing a high level of burnout, doctors reduced their professional investment, and did not take on extra efforts for their organization, and developed a negative attitude towards their work. If doctors' psychological attachment to their organization decreased due to burnout, it is not surprising, that a sense of a 'calling' was no longer an occupational goal,so the doctors no longer viewed their careers as a calling.

As the Conservation of Resources (COR) Theory pointed out, when doctors lost their resources or invested them but did not reap the expected reward, they exhibited psychological pressure and detachment from their organization [56]. Burnout appears when doctors lose their resources and are unable to supplement their cognitive, emotional, and physical abilities [47]. The high level of job burnout among doctors provides a relatively low assessment of gains leisure and vital, spiritual, familial, material, and political resources, which can lead to further detachment from their medical service [56]. As detachment occurs, problems such as physicians being 'physically uninvolved in services, cognitively unvigilant, and emotionally disconnected from others in ways that hide what they think and feel, their creativity, and beliefs and values' likely arise. Therefore, the act of 'providing services for people' is no longer regarded as part of the doctor's career goals and motivations [10]. Even worse, it can further affect doctors' beliefs, attitudes, and behaviours about their careers with possible consequences for career identity and dependence as well as the norms and spirit of Chinese health care overall. Increased job burnout subsequently reduces the degree of a doctor's psychological attachment to his or her organization, increasing professional turnover and also lowering the sense of medicine as a 'calling'. Therefore, hospital managers should pay greater attention to symptoms of job burnout in subordinate doctors, and make significant efforts toward developing strategies that strengthen doctors' psychological attachments to their organization as well as their sense of career calling.

\section{Limitations}

This study offered a number of interesting discoveries. However, some limitations should be considered. Firstly, this cross-sectional survey was conducted by administering with an online questionnaire, and a snowball sampling methodology was used, which increased the potential for sampling bias, e.g., there are differences in the response rate of doctors in different provinces. Secondly, the cross-sectional nature of this study prevented establishment of causation related to the causal relationship between job burnout, psychological attachment, and career calling; ultimately, these results could not be regarded as describing a causal relationship. Thirdly, data were collected from the self-reports of doctors, which introduced response bias from social desirability or negative affection. Finally, we used foreign scales that ignored issues of cross-cultural adaptability, which offers scope for academic attention in the future. The issue of job burnout is common in hospital settings, and its influence is extensive and pervasive; therefore, longitudinal studies should be conducted in the future.

\section{Conclusions}

This study revealed the prevalence of burnout syndrome among doctors (85.79\%) in China's hospital settings and its related factors. A key to implementation of our study's findings is that hospital managers should take effective measures to prevent and relieve the symptoms of doctor burnout, especially focusing on doctors who are prone to job burnout, such as younger physicians and attending physicians with longer daily working hours.

According to our survey, Chinese doctors encountered burnout frequently, leading to negative effects such as a low degree of psychological attachment to their organization and sense of medicine as a 'career calling'. In addition, this study was found that job burnout threatened career calling by weakening doctors' psychological attachment to their organization. Another key to implementation of our study's findings is to enhance career calling of doctors by strengthening doctors' attachment to medical organizations. Namely, it is high time to take some measures to give doctors more humanistic care, improve their career development path and reduce their daily working hours in order to enhance their job attachment and career calling. Definitively, some new perspectives for future research were also provided by this study. 


\section{Abbreviations}

B: Unstandardized regression coefficients; CHFPSY: Chinese Health and Family Planning Statistical Yearbook; COR: Conservation of Resources; DA: Depersonalization; EE: Emotional Exhaustion; M: Mean; PA: Personal Accomplishment; SD: Standard Deviations; SE: Standard Error

\section{Acknowledgments}

We thank those who made the study possible: students, teachers, friends, parents, and school staff and thank all participants who helped in collecting data and distributing questionnaires to other subjects. In addition,we also thank peer review for their efforts to improve the quality of manuscripts. They are Dr. Ahmed Mohammed Abbas, Dr. African aeenbarast, and Dr. Marc Saez, respectively.

\section{Authors' contributions}

TS and DPC co-designed the research. FJL, DY, YS and MZ performed the research. SEZ and TS analyzed the data. FZX and JHW contributed materials and analysis tools. SEZ and TS wrote and revised the manuscript. HYY and LBY substantively revised it. All authors read and approved the final manuscript.

\section{Funding}

This study was funded by the Key project of Heilongjiang Provincial Education Science Planning (No. GJA1214002) led by Depin Cao.

\section{Availability of data and materials}

Data is currently not available online, but the data can be obtained upon request from hydzhangshue@163.com.

\section{Ethics approval and consent to participate}

The Institutional Review Board (IRB) of Harbin Medical University approved this study. Since the survey was anonymous, it was impossible to obtain informed written consent. In this case, an informed consent form was included at the beginning of the questionnaire. Completing the questionnaire was therefore considered 'informed consent' for participation in the survey. Confidentiality was maintained for all information collected in the survey.

\section{Consent for publication}

Not applicable.

\section{Competing interests}

The authors declare that they have no competing interests.

\section{Author details}

${ }^{1}$ Department of Health Management, School of Health Management, Harbin Medical University, Harbin 150081, China. ${ }^{2}$ Student Grade department, College of Bioinformatics Science and Technology, Harbin Medical University, Harbin 150081, China. ${ }^{3}$ Department of Health Management, School of Health Management, Harbin Medical University, Harbin 150086, China. ${ }^{4}$ Department of Anesthesiology, The first Affiliated Hospital, Harbin Medical University, Harbin 150010, China. ${ }^{5}$ Center for Higher Education Research and Teaching Quality Evaluation, Harbin Medical University, Harbin 150081, China. ${ }^{6}$ Department of Health Management, School of Medicine, Hangzhou Normal University, Hangzhou 311121, China.

\section{Received: 15 June 2019 Accepted: 14 February 2020} Published online: 12 March 2020

\section{References}

1. Wang Y, Li X, Zhou M, Luo S, Liang J, Liddell CA, Coates MM, Gao Y, Wang L, He C. Under-5 mortality in 2851 Chinese counties, 1996-2012: a subnational assessment of achieving MDG 4 goals in China. Lancet. 2016; 387(10015):273-83.

2. Fullman N, Yearwood J, Abay SM, Abbafati C, Abd-Allah F, Abdela J, Abdelalim A, Abebe Z, Abebo TA, Aboyans V. Measuring performance on the healthcare access and quality index for 195 countries and territories and selected subnational locations: a systematic analysis from the global burden of disease study 2016. Lancet. 2018;391(10136):2236-71.

3. Wu H, Liu L, Wang Y, Gao F, Zhao X. Factors associated with burnout among Chinese hospital doctors: a;cross-sectional study. BMC Public Health. 2013;13(1):786.
4. Silva JLLD, Soares RDS, Costa FDS, Ramos DDS, Lima FB, Teixeira LR. Psychosocial factors and prevalence of burnout syndrome among nursing workers in intensive care units. Revista Brasileira De Terapia Intensiva. 2015; 27(2):125-33.

5. Wu H, Zhao Y, Wang JN, Wang L. Factors associated with occupational stress among Chinese doctors: a cross-sectional survey. Int Arch Occup Environ Health. 2010;83(2):155-64.

6. Shoji K, Cieslak R, Smoktunowicz E, et al. Associations between job burnout and self-efficacy: a meta-analysis. Anxiety Stress Coping. 2016;29(4):367-86.

7. Laeeque SH, Bilal A, Hafeez A, Khan Z. Violence breeds violence: burnout as a mediator between patient violence and nurse violence. Int J Occup Saf Ergonomics Jose. 2018;5:1-31.

8. Dik BJ, Duffy RD, Eldridge BM. Calling and vocation in career counseling: recommendations for promoting meaningful work. Prof Psychol Res Pract. 2009:40(6):625-32.

9. Swider BW, Zimmerman RD. Born to burnout: a meta-analytic path model of personality, job burnout, and work outcomes. J Vocat Behav. 2010;76(3):487-506.

10. Creed PA, Rogers ME, Praskova A, Searle J. Career calling as a personal resource moderator between environmental demands and burnout in Australian junior doctors. J Career Dev. 2014;41(6):547-61.

11. Maslach C, ., Schaufeli WB, Leiter MP: Job burnout. Annu Rev Psychol 2001, 52(1):397-422.

12. Åsa LN, Jonsdottir $H$, Julie $P$, Gunnar A. Internal construct validity of the ShiromMelamed burnout questionnaire (SMBQ). BMC Public Health. 2012;12(1):1.

13. Liu HT. The reason and the countermeasure of the University Instructor's job burnout. Hunan Vocat Coll National. 2009;05(1):75-9.

14. Rouleau D. The effects of midwives' job satisfaction on burnout, intention to quit and turnover: a longitudinal study in Senegal. Hum Resour Health. 2012;10(1):9.

15. Grau A, Suñer R, García MM. Burnout syndrome in health workers and relationship with personal and environmental factors. Gac Sanit. 2016;19(6):463-70.

16. Wu S, Li ZH, Wang Z, Wang M. Relationship between job burnout and occupational stress among doctors in China. Stress Health. 2010;24(2):143-9.

17. Rotenstein LS, Torre M, Ramos MA, Rosales RC, Guille C, Sen S, Mata DA Prevalence of burnout among physicians: a systematic ReviewPrevalence of burnout among PhysiciansPrevalence of burnout among physicians. JAMA. 2018:320(11):1131-50.

18. Schwenk TL, Gold KJ. Physician burnout-a serious symptom, but of what?Symptoms of burnout among PhysiciansEditorial. JAMA. 2018;320(11): 1109-10.

19. Zhang AL, Zhang QD. Research on the cultivation of the medical personnel professional spirit. Acta Universitatis Medicinalis Nanjing. 2012;12(01):60-62.

20. Hirschi A. Callings in career: a typological approach to essential and optional components. J Vocat Behav. 2011;79(1):60-73.

21. Pai DD, Lautert L, Souza SB, Marziale MH, Tavares JP. Violence, burnout and minor psychiatric disorders in hospital work. Revista Da Escola De Enfermagem Da U S P. 2015;49(3):457-64

22. Praskova A, Creed PA, Hood M. Self-regulatory processes mediating between career calling and perceived employability and life satisfaction in emerging adults. J Career Dev. 2015;42(2):86-101.

23. Duffy RD, Sedlacek WE. The salience of a career calling among college students: exploring group differences and links to religiousness, life meaning, and life satisfaction. Career Dev Q. 2011;59(1):27-41.

24. Praskova A, Creed PA, Hood M. The development and initial validation of a career calling scale for emerging adults. J Career Assess. 2015;23(1):91-106.

25. Zhou X, Pu J, Zhong X, Zhu D, Yin D, Yang L, Zhang Y, Fu Y, Wang H, Xie P. Burnout, psychological morbidity, job stress, and job satisfaction in Chinese neurologists. Neurology. 2017;88(18):1727-35.

26. Bies RJ. Organizational Citizenship Behavior: The Good Soldier Syndrome, by Dennis W. Organ. Adm Sci Q. 1988;41(6):692-703.

27. Luchak AA. What kind of voice do loyal employees use? Br J Ind Relat. 2003:41(1): 115-34.

28. Meyer JP, Bobocel DR, Allen NJ. Development of organizational commitment during the first year of employment: a longitudinal study of pre- and postentry influences. J Manage Official J South Manage Assoc. 1991;17(4):717-33.

29. Peng J, Jiang $X$, Zhang J, Xiao R, Song Y, Feng X, Zhang Y, Miao D. The impact of psychological capital on job burnout of Chinese nurses: the mediator role of organizational commitment. PLoS One. 2013;8(12):e84193.

30. Adam F, Val W. The impact of general practice attachments on foundation doctors: achieving the goals of Modernising medical careers. Educ Primary Care. 2011;22(5):314-20. 
31. Burris ER, Detert JR, Chiaburu DS. Quitting before leaving: the mediating effects of psychological attachment and detachment on voice. J Appl Psychol. 2008;93(4):912.

32. Commission NHaFP: Chinese health and family planning statistical yearbook 2016.

33. Grossman Z, Chodick G, Kushnir T, Cohen HA, Chapnick G, Ashkenazi S. Burnout and intentions to quit the practice among community pediatricians: associations with specific professional activities. Israel J Health Policy Res. 2019;8(1):2.

34. Li C, Kan S. The influence of distributive justice and procedural JUSTI CE on job burnout. Acta Psychol Sin. 2003;35(5):677-84

35. Qiao Z, Lu C, Chen M, Xin G, Lin W, Yang J, Yang J, Tang Q, Yang X, Qiu X. Prevalence and factors associated with occupational burnout among HIV/ AIDS healthcare workers in China: a cross-sectional study. BMC Public Health. 2016;16(1):335.

36. Long-Fei LI, Yang XX, Wang F. Study on job burnout and personality characteristics of teachers. Chinese Primary Health Care. 2013(01):31-2.

37. Yong-Xin LI. Relationship among job burnout,self-esteem,health and intention to quit of nurses. Chin J Nurs. 2007:42(5):332-9.

38. Liang J. Ethical leadership and employee voice: examining a moderatedmediation model. Acta Psychol Sin. 2014;46(2):252-64.

39. Dik BJ, Eldridge BM, Steger MF, Duffy RD. Development and validation of the calling and vocation questionnaire (CVQ) and brief calling scale (BCS). J Career Assess. 2012;20(3):242-63.

40. Xie B, Xia M, Xin X, et al. Linking calling to work engagement and subjective career success: The perspective of career construction theory. J Vocational Behav. 2016;94:70-8.

41. Hayes A. Introduction to mediation, moderation, and conditional process analysis. J Educ Meas. 2013;51(3):335-7.

42. Guenette JP, Smith SE. Burnout : job resources and job demands associated with low personal accomplishment in United States radiology residents. Acad Radiol. 2018;25(6):739-43.

43. Chamberlain SA, Gruneir A, Hoben M, Squires JE, Cummings GG, Estabrooks CA. Influence of organizational context on nursing home staff burnout: a cross-sectional survey of care aides in Western Canada. Int J Nurs Stud. 2017;71:60-9.

44. Rössler W. Stress, burnout, and job dissatisfaction in mental health workers. Eur Arch Psychiatry Clin Neurosci. 2016;266(4):1-1.

45. Wang Z, Xie Z, Dai J, Zhang L, Huang Y, Chen B. Physician burnout and its associated factors: a cross-sectional study in Shanghai. J Occup Health. 2005;56(1):73-83.

46. Bolino MC, Turnley WH. The personal costs of citizenship behavior: the relationship between individual initiative and role overload, job stress, and work-family conflict. J Appl Psychol. 2005;90(4):740.

47. Głebocka A, Lisowska E. Professional burnout and stress among Polish physicians explained by the Hobfoll resources theory. J Physiol Pharmacol. 2007;58 suppl 5(Pt1):243-52.

48. Wang Y, Liu L, Wang J, Wang L. Work-family conflict and burnout among Chinese doctors: the mediating role of psychological capital. J Occup Health. 2012;54(3):232.

49. Chirico F. Job stress models for predicting burnout syndrome: a review. Ann Ist Super Sanita. 2016;52(3):443-56.

50. Hu NC, Chen JD, Cheng TJ. The associations between Long working hours, physical inactivity, and burnout. J Occup Environ Med. 2016;58(5):514-8.

51. Yang S, Liu D, Liu H, Zhang J, Duan Z. Relationship of work-family conflict, self-reported social support and job satisfaction to burnout syndrome among medical workers in Southwest China: a cross-sectional study. PLoS One. 2017;12(2):e0171679.

52. Fielden SL, Peckar CJ. Work stress and hospital doctors: a comparative study. Stress Health. 2015;15(3):137-41.

53. Jovanović N, Podlesek A, Volpe U, Barrett E, Ferrari S, Rojnic KM, Wuyts P, Papp S, Nawka A, Vaida A. Burnout syndrome among psychiatric trainees in 22 countries: risk increased by long working hours, lack of supervision, and psychiatry not being first career choice. Eur Psychiatry. 2016;32:34-41.

54. Hobfoll SE. Traumatic stress: a theory based on rapid loss of resources. Anxiety Res. 1991;4(3):187-97.

55. Sack WH. Staff burnout: job stress in the human services. J Am Acad Child Psychiatry. 1982;21(3):311-2.

56. Benson NM, Chaukos D, Vestal H, Chad-Friedman EF, Denninger JW, Cpc B. A qualitative analysis of stress and relaxation themes contributing to burnout in first-year psychiatry and medicine residents. Acad Psychiatry. 2018;(42):1-6.

\section{Publisher's Note}

Springer Nature remains neutral with regard to jurisdictional claims in published maps and institutional affiliations.
Ready to submit your research? Choose BMC and benefit from:

- fast, convenient online submission

- thorough peer review by experienced researchers in your field

- rapid publication on acceptance

- support for research data, including large and complex data types

- gold Open Access which fosters wider collaboration and increased citations

- maximum visibility for your research: over $100 \mathrm{M}$ website views per year

At BMC, research is always in progress.

Learn more biomedcentral.com/submissions 